\title{
Influence of Graphene Oxide Incorporation on Resorcinol- Formaldehyde Polymer and Carbon Aerogels
}

\author{
Balázs Nagy¹, Andrea Domán¹, Alfréd Menyhárd', Krisztina László1* \\ ${ }^{1}$ Department of Physical Chemistry and Materials Science, Faculty of Chemical Technology and Biotechnology, \\ Budapest University of Technology and Economics, H-1521 Budapest, P.O. Box 91, Hungary \\ *Corresponding author, e-mail: klaszlo@mail.bme.hu
}

Received: 27 July 2018, Accepted: 24 October 2018, Published online: 05 November 2018

\begin{abstract}
Resorcinol-formaldehyde based polymer hydrogels with various graphene oxide (GO) content were synthesized using $\mathrm{Na}_{2} \mathrm{CO}_{3}$ as catalyst at $\mathrm{pH}=6$ conditions. After supercritical drying they were converted to carbon aerogels in nitrogen atmosphere. The heat treatment not only pyrolysed the polymer gel, but also reduced GO. The GO added varied within 0-14\% related to the mass of resorcinol which resulted in the reinforcement of the polymer matrix. The texture of the polymer and the carbon aerogels were characterized and compared in the nanoscale using SEM and TEM imaging, X-ray diffraction (XRD) and low temperature nitrogen adsorption measurements. The transition from polymer to carbon state was studied by thermogravimetry. In agreement with reference works in the GO range studied the morphology was not affected by the GO content either in the polymer or in the carbon form. The direct current (DC) conductivity however linearly increased with the added GO and already $10 \%$ doubled the conductivity of the plain carbon aerogel.
\end{abstract}

Keywords

porous polymer, carbon aerogel, graphene oxide, gas adsorption, electric conductivity

\section{Introduction}

Carbon aerogels are most often obtained from aqueous resorcinol $(\mathrm{R})$ - formaldehyde $(\mathrm{F})$ precursor solution following the synthesis route first proposed by Pekala [1]. The versatility of both the properties and the application of these materials originates from the adaptability of the sol-gel technology used in the first step of synthesis. The morphology of both the polymer and the carbon gel can be further tuned by the technique of solvent removal or by selecting a different solvent as a reaction medium with porogenic effect. The sol - gel technique also opens the avenue for introducing various "additives" at practically any of the stages of the preparation. Co-monomers, metal ions or nanoparticles can be added already to the precursor solution or to the dry polymer, prior to converting the polymer to carbon material. The textural and chemical characteristics of carbon aerogels, which are simultaneously micro-, meso- and macroporous, predispose them as thermal and phonic insulators, electric double layer and super capacitors, chromatography packing, adsorbents, catalyst supports, etc. [2-5]. In spite of the open pore system a drawback of aerogels for dynamic use is their inherently random pore morphology, which may hinder and thus make it difficult to predict the mass transport properties. 3D printing is proposed to engineer the macropore architecture in order to easily custom-build the mass transport. Thus, applications that rely on the transport of some species through aerogels (e.g., energy storage, filtration, desalination, catalysis, etc.) can take advantage of optimally tailored pore morphology in 3D-printed aerogels to maximize their performance [6-7].

Among aerogels the advantage of carbons compared to the inorganic metal oxide aerogels is that although they are very good thermal insulators but conduct electricity. Nevertheless, the energy density and power density need to be further improved if we aim for electrode material application. High electrical conductivity e.g., for fuel cell catalyst application is important to minimize ohmic losses associated with the electron transfer [8]. Nanosized carbon materials hold promise as fillers for enhancing the capacitance performance of carbon aero or xerogels [9-10]. Carbon nanoparticles, e.g., graphene derivatives, due to their outstanding physical and chemical properties and the coupled benign consequences of these phenomena in materials science are an obvious choice for increasing the 
electric conductivity [11]. Incorporating particles into the carbon aerogel matrix may effectively increase the electrical properties [12-13]. Particularly graphene, the novel 2D carbon material, has great potential as electrode material, filler or ingredient for carbon. The hydrophobicity of graphene nonetheless prevents its convenient use in aqueous systems. The hydrophilic graphene oxide (GO) can be an alternative additive, as it is converted to a graphene like species during the pyrolysis of the composite.

Graphene - carbon gel composite materials were systematically studied by Worsley et al in high $\mathrm{GO} / \mathrm{R}$ ratio mixtures. The RF gel in low concentration was intended to act as a crosslinker to enhance the electrical conductivity of the GO aerogel after carbonization, which successfully reduced the oxygen of the GO-RF gel form $17 \%$ to $1 \%$. [14-15]. No $\mathrm{RF}$ derived particles decorated the graphene sheets even at $56 \mathrm{~m} / \mathrm{m} \% \mathrm{RF}$ concentration. They assumed that the organic precursors added at sufficiently low concentrations to the GO suspension form covalent interconnections preferentially through the oxygen functionalities of the GO between individual sheets. The large increase in surface area with increasing amount of RF was attributed to the higher degree of exfoliation. They found that already a few $\%$ of $\mathrm{RF}$ increased the conductivity of the pure graphene aerogel from $0.25 \mathrm{~S} / \mathrm{cm}$ to $0.87 \mathrm{~S} / \mathrm{cm}$. The bulk electrical conductivity of the RF doped graphene aerogel was more than 2 orders of magnitude greater than macroscopic 3D graphene networks prepared with only physical cross-links.

The aim of our work was to reveal the influence of added $\mathrm{GO}$ at much lower GO content and study the effect not only on the carbon aerogels but also on the precursor resorcinol - formaldehyde polymer aerogels. Graphene oxide was therefore added to the aqueous precursor solution with increasing amount prior to the sol - gel synthesis. The hydrogels, after supercritical extraction, were converted to carbon aerogels. The morphology of the polymer and carbon gels was characterized by scanning and transmission electron microscopy (SEM, TEM), low temperature nitrogen adsorption/desorption and powder X-ray diffraction.
Thermogravimetry (TGA) was employed to determine the thermal decomposition to optimize the pyrolysis temperature. The electric conductivity was tested by following the resistivity in direct current (DC).

\section{Experimental}

\subsection{Materials}

A ca. $1 \mathrm{~m} / \mathrm{m} \%$ aqueous suspension of graphene oxide (GO) was prepared from natural graphite (Graphite Tyn, China) by the improved Hummers' method [16]. RF hydrogels were prepared by the aqueous polycondensation reaction of resorcinol (R) and formaldehyde (F) by the method of Lin and Ritter [17]. Briefly, R (Merck), F (37\% in water, Merck) and the catalyst sodium carbonate ( $99 \%$, Merck) were dissolved in distilled water. The $\mathrm{R} / \mathrm{F}$ and $\mathrm{R} / \mathrm{Na}_{2} \mathrm{CO}_{3}$ molar ratios were 0.5 and 50 , respectively. The overall concentration was $5 \mathrm{~m} / \mathrm{m} \%$. The GO containing gels were prepared by replacing the distilled water with a dilute GO suspension. The initial $\mathrm{pH}$ of the solution was adjusted to $\mathrm{pH}$ 6.0 with dilute $\mathrm{HNO}_{3}$ (Merck). After thorough stirring at room temperature the sol sealed in vials was kept at $85{ }^{\circ} \mathrm{C}$ for 1 week to complete the gelation. The polymer hydrogels were dried by supercritical $\mathrm{CO}_{2}$ and converted to carbon by heat treatment in inert atmosphere (rotating quartz reactor, dry $\mathrm{N}_{2}$ atmosphere, $800^{\circ} \mathrm{C}$ ) (Fig. 1). A detailed description of the synthesis is given elsewhere [18]. The polymer and carbon aerogel samples are labelled as PX and CX, respectively, where $\mathrm{X}$ is the amount of the GO added to the precursor solution as $\mathrm{m} / \mathrm{m} \%$, referred to R. The GO content of the precursor solution was set in the $0-14 \%$ range.

\subsection{Methods}

The texture of the samples was characterized by scanning and transmission electron microscopy (SEM and TEM, respectively) (Hitachi SU8030 and JEM2100). The elastic modulus was measured on isometric $(1.2 \times 1.2 \mathrm{~mm})$ hydrogel cylinders using an INSTRON 5543 mechanical testing instrument at ambient temperature. The elastic modulus was determined in the small deformation region by
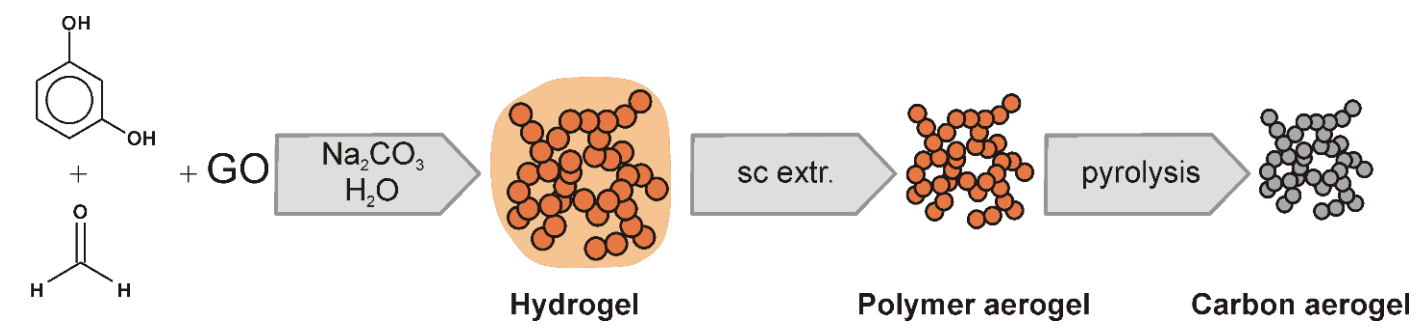

Fig. 1 Synthesis scheme of GO doped carbon aerogels 


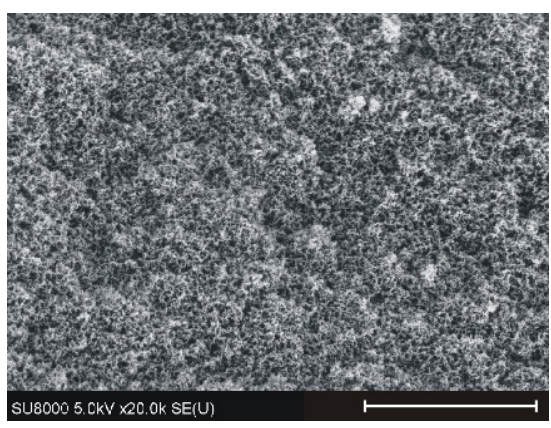

(a)

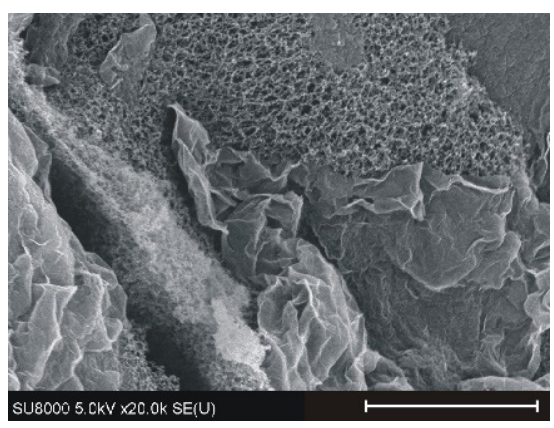

(b)

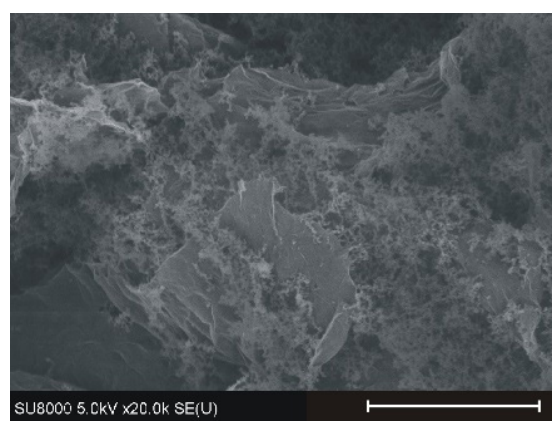

(c)

Fig. 2 SEM images of the P00 (a), the P05 (b) and the P14 (c) samples. The scale bars are 2

the method of Horkay and Zrínyi [19]. Thermogravimetric analysis (TGA) was performed on a Perkin Elmer STA6000 apparatus. The samples were placed in alumina crucibles and heated from room temperature to $900{ }^{\circ} \mathrm{C}$ at a heating rate of $10^{\circ} \mathrm{C} / \mathrm{min}$ under a flow of nitrogen $(20 \mathrm{~mL} /$ min) as purge gas. The nitrogen adsorption/desorption isotherms were measured at $-196{ }^{\circ} \mathrm{C}$ with a Nova2000e (Quantachrome) computer controlled apparatus.

The apparent surface area $\mathrm{S}_{\mathrm{BET}}$ was calculated using the Brunauer-Emmett-Teller (BET) model [20]. The total pore volume $\left(\mathrm{V}_{0.95}\right)$ was derived from the amount of nitrogen adsorbed at relative pressure 0.95 , assuming that the pores are then filled with liquid adsorbate. The micropore volume $\left(\mathrm{W}_{0}\right)$ was derived from the DubininRadushkevich (DR) plot [21]. For the sake of comparison the pore size distribution (PSD) in the mesoporous range was calculated with the Barret-Joyner-Halenda (BJH) model [22]. Transformation of the primary adsorption data and pore size analysis were performed with the Quantachrome ASiQwin software (version 3.0). The powder X-ray diffraction (XRD) was measured in the range $2 \Theta=4-84^{\circ}$ with an X'pert Pro MPD (PANanalytical Bv., The Netherlands) X-ray diffractometer using an $\mathrm{X}$ 'celerator type detector and $\mathrm{Cu} \mathrm{K}_{\alpha}$ radiation with a $\mathrm{Ni}$ filter foil ( $\lambda=1.5408 \AA$ ) on a 'zero-background Si-single crystal' sample holder.

\section{Results and discussion}

\subsection{Characterization of the polymer gels}

In this work we aim for the comparison of GO incorporation in the polymer precursors and the carbon obtained from them. SEM images show that the presence of the GO does not modify the well-known globular shape of the polymer units. It is also confirmed that the GO is well distributed in the matrix due to its high oxygen content. The $\mathrm{C} / \mathrm{O}$ ratio of this $\mathrm{GO}$, determined by XPS, was 1.8 [23].
Interestingly, polymer beads do not develop on the surface of the GO sheets, however, at the highest GO content (14\%) scarcely decorate the GO edges.

Fig. 3 reveals that the incorporation of the GO resulted in the expected reinforcement of the polymer. Increasing the GO content also results in the development of voids (see also Fig. 2(b)-(c)). Some of them are visible with naked eye and compromise the compressibility measurements at higher nanoparticle concentration. The observed trend is not linear and similar to the one experienced on GO doped poly(N-isopropylacrylamide) hydrogels [24].

As expected, the supercritical drying is a very gentle way of solvent removal [18]. This was characterized by the relative diameter of the obtained rod-like samples as compared to the size of the hydrogels. In our case it resulted only a ca $20 \%$ shrinkage in the GO free polymer. The effect is even more modest in the GO doped aerogels indicating that the GO hampers the shrinkage during the supercritical drying (Fig. 4). Such effect in the carbonized state is even more obvious and concomitantly results in the decrease of the apparent density. The limited shrinkage in the carbon state was reported by other groups [25-27].

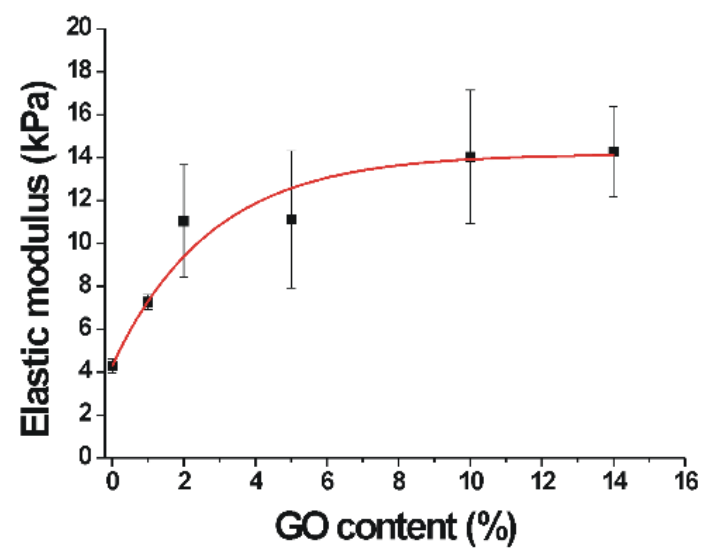

Fig. 3 Influence of the GO/resorcinol ratio (\%) on the stiffness of the hydrogel. Symbols are measured values, the red line is guide for the eye. 


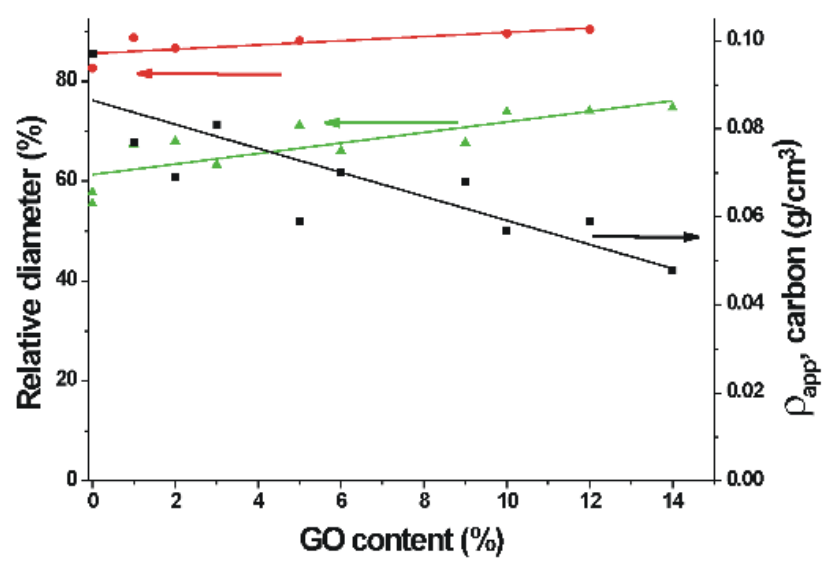

Fig. 4 Influence of the incorporated GO on the diameter of the polymer and carbon aerogels and the apparent density of the latter. The diameter of the hydrogels was used as reference. Symbols: red dots: size of the

polymer aerogel, green triangles: size of the carbon aerogel, black squares: apparent density of the carbon aerogels. Symbols are measured values, the lines are guide for the eye.

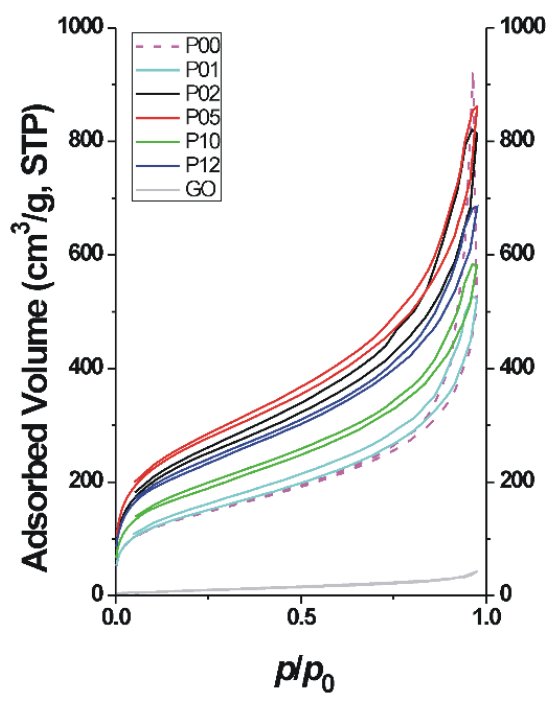

(a)

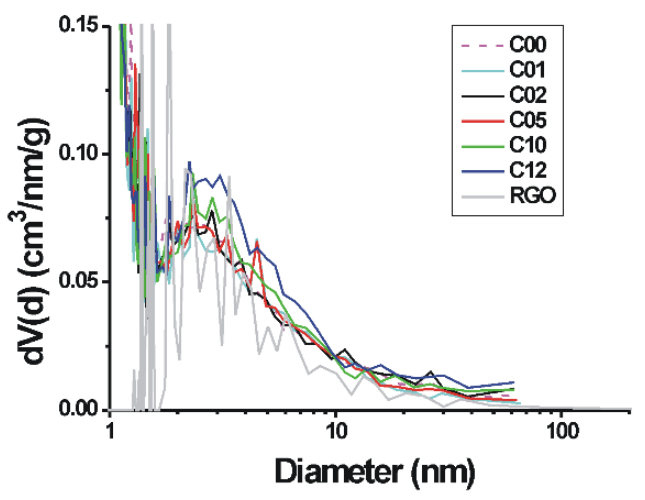

(c)
The low temperature nitrogen adsorption/desorption isotherms were measured to reveal the nanoscale texture of the polymer aerogels (Fig. 5(a)). All the isotherms belong to Type IV based the recent recommendation of the IUPAC [28]. The initial monolayer-multilayer adsorption on the mesopore walls is followed by pore condensation. The hysteresis loop typical to almost all mesoporous materials is of Type $\mathrm{H} 3$, and its width is the most recognizable in the GO free polymer sample. In these systems this kind of hysteresis indicates a pore network of macropores which are not completely filled with liquid nitrogen even at relative pressure $\mathrm{p} / \mathrm{p}_{0}=1$. The initial section of the isotherms reveals a gradual curvature (i.e., a less distinctive Point B), implying a significant overlap of monolayer coverage and the onset of multilayer adsorption. The influence of the added GO is not systematic, but generally speaking it increases the adsorption in the entire relative pressure range. We have to comment here as well, that low temperature adsorption on

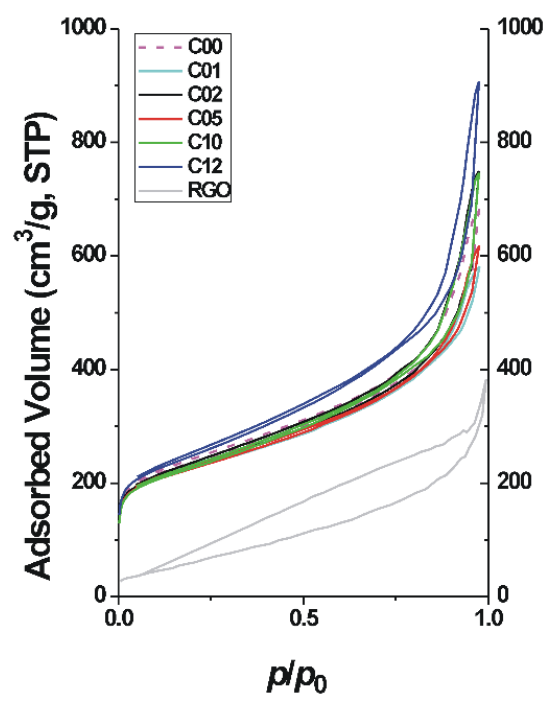

(b)

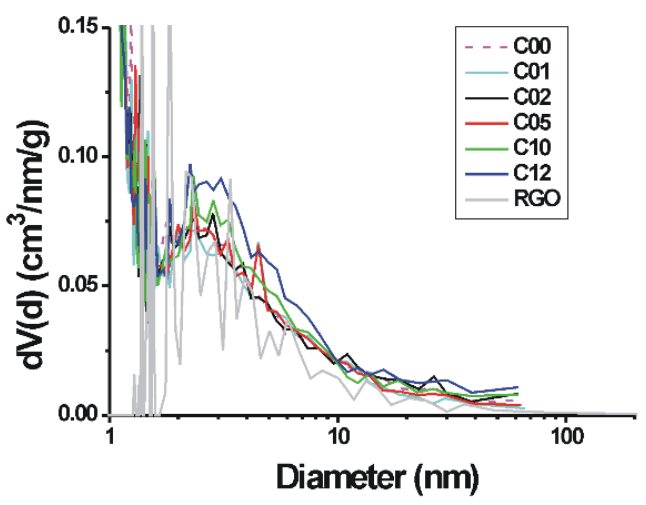

(d)

Fig. 5 Low temperature $\left(-196^{\circ} \mathrm{C}\right)$ nitrogen adsorption isotherms of selected polymer (a) and carbon (b) aerogels; pore size distribution of the polymer (c) and carbon (d) gels calculated from the adsorption branch by the $\mathrm{BJH}$ model 
polymer materials often result in the swelling of the nonrigid system. In our case, if this phenomenon is relevant, the swelling is reversible, as low pressure hysteresis was not observed in any of the polymer samples. The BJH pore size distribution curves are very similar and reveal a continuous distribution in the mesopore and narrower macropore range without any distinguishable feature (Fig. 5(c)). The numeric data, the apparent surface area, the microand total pore volume calculated for both the polymer and carbon samples are listed in Table 1. No systematic effect on the surface area or on the micropore volumes is observable, but the trend of $\mathrm{V}_{0.95}$ and thus $\mathrm{V}_{\text {meso }}=\mathrm{V}_{0.95}-\mathrm{W}_{0}$ show a decent increase as the GO content is increasing.

\subsection{Conversion to carbon}

According to the thermograms, the GO in this quantity has no significant influence on the thermal degradation of the RF polymer (Fig. 6). The sharp decomposition of the GO has no sign in the TG and DTG curves of any of the composite samples. A detailed study of Hummers GO characterisation including their thermal behaviour was published recently [29]. Based on the TG response $800^{\circ} \mathrm{C}$ was selected for the carbonization, where the residue varied in the 46-50\%. This well agreed with the macroscopic yield after the pyrolysis (44-52\%) and also no systematic trend related to the GO content was found. The carbonization also results in further axial shrinkage with the same trend observed during the drying implying that the reduced graphene oxide retains the scaffolding effect of the GO. Accordingly, the apparent density of the carbonised rods decreases with the GO content (Fig. 4). It was reported that pyrolysis of the carbon aerogels at $1050{ }^{\circ} \mathrm{C}$ in nitrogen atmosphere resulted in a successful reduction of

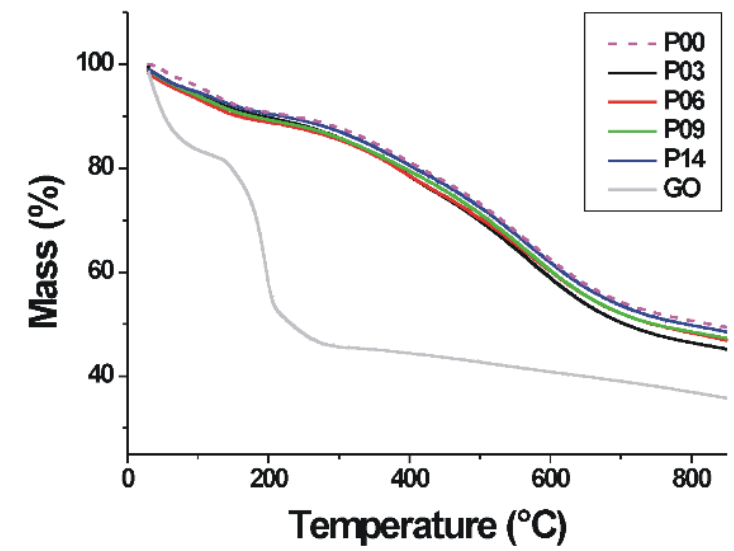

(a)
Table 1 Data from the low temperature $\left(-196^{\circ} \mathrm{C}\right)$ nitrogen adsorption isotherms

\begin{tabular}{|c|c|c|c|c|c|}
\hline & Aerogels & $S_{B E T}$ & $W_{0}$ & $V_{0.95}$ & $V_{\text {meso }}$ \\
\hline & $\begin{array}{c}\text { GO content, } \\
\%\end{array}$ & $\mathrm{~m}^{2} / \mathrm{g}$ & $\mathrm{cm}^{3} / \mathrm{g}$ & $\mathrm{cm}^{3} / \mathrm{g}$ & $\mathrm{cm}^{3} / \mathrm{g}$ \\
\hline \multirow[t]{2}{*}{ GO } & 100 & 36 & 0.01 & 0.06 & 0.05 \\
\hline & $\begin{array}{c}\text { RGO } \\
100\end{array}$ & 230 & 0.06 & 0.40 & 0.34 \\
\hline \multirow{10}{*}{ 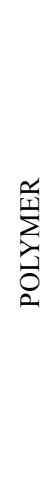 } & $0 \%$ & 503 & 0.18 & 0.67 & 0.49 \\
\hline & $1 \%$ & 508 & 0.19 & 0.70 & 0.91 \\
\hline & $2 \%$ & 848 & 0.31 & 1.06 & 0.75 \\
\hline & $3 \%$ & 535 & 0.20 & 0.73 & 0.53 \\
\hline & $5 \%$ & 948 & 0.34 & 1.13 & 0.79 \\
\hline & $6 \%$ & 555 & 0.19 & 0.75 & 0.56 \\
\hline & $9 \%$ & 659 & 0.23 & 0.83 & 0.60 \\
\hline & $10 \%$ & 637 & 0.22 & 0.79 & 0.57 \\
\hline & $12 \%$ & 786 & 0.28 & 0.94 & 0.66 \\
\hline & $14 \%$ & 588 & 0.21 & 0.78 & 0.57 \\
\hline \multirow{10}{*}{ 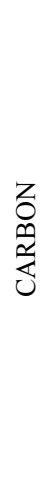 } & $0 \%$ & 856 & 0.34 & 0.87 & 0.43 \\
\hline & $1 \%$ & 823 & 0.33 & 0.81 & 0.48 \\
\hline & $2 \%$ & 827 & 0.33 & 0.90 & 0.57 \\
\hline & $3 \%$ & 853 & 0.34 & 0.91 & 0.57 \\
\hline & $5 \%$ & 809 & 0.33 & 0.83 & 0.50 \\
\hline & $6 \%$ & 829 & 0.33 & 0.94 & 0.61 \\
\hline & $9 \%$ & 894 & 0.36 & 1.21 & 0.85 \\
\hline & $10 \%$ & 812 & 0.33 & 0.91 & 0.58 \\
\hline & $12 \%$ & 885 & 0.35 & 1.07 & 0.72 \\
\hline & $14 \%$ & 838 & 0.33 & 1.15 & 0.82 \\
\hline
\end{tabular}

the oxygen content (form $17 \%$ to $1 \%$, by XPS) [14]. We presume that GO also loses most of its oxygen and will be considered here as reduced graphene oxide (RGO). The $\mathrm{C} / \mathrm{O}$ atomic ratio increased from 2 to 4 when the $\mathrm{GO}$ after

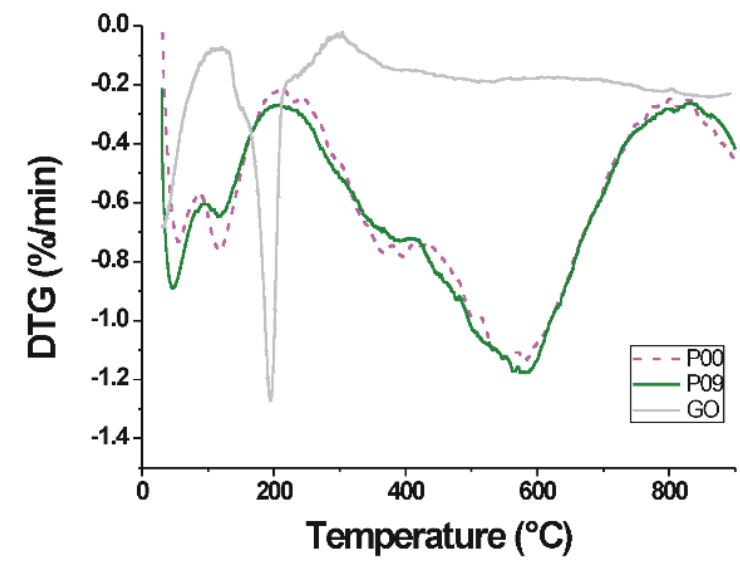

(b)

Fig. 6 Thermograms and the derivative curves of GO and selected polymer aerogels in nitrogen atmosphere 
a treatment at $800^{\circ} \mathrm{C}$ in nitrogen atmosphere. (No particular caution was taken against re-oxidation after removal from the reactor in cold state.)

In the X-ray diffractograms (Fig. 7) the samples are amorphous, their only characteristic feature is the wide signals around $2 \Theta \mathrm{ca} 22^{\circ}$ and $44^{\circ}$. The flat peaks corresponding to about 3.5-4 $\AA$ confirm the presence of a loose layered structure. That is, as expected, no long range order develops under the heat treatment conditions applied. It was shown recently however, that near $2000^{\circ} \mathrm{C}$ a high surface area distorted graphene sheet structure is formed [30].

\subsection{Characterization of the carbon samples}

The nitrogen adsorption isotherms (Fig. 5(b)) are very similar to the ones measured on the polymer gels. The Type IV is typical for these systems as well as the $\mathrm{H} 3$ hysteresis $[13,31]$. The isotherms corresponding to the different GO content practically overlap. In the carbons, however, the initial slope is much steeper and the knee corresponding to the B point is sharper. The enhanced adsorption is related to an increase in the micropore volume. The carbonization results in the formation of micropores in the spherical beads constructing the RF based carbon aerogels during the carbonization. Due to the lack of the corresponding kernel files no DFT based methods can be used for the pore size distribution of the polymer sample, we use the BJH model for the carbonized samples as well. The pore size distribution is much more characteristic: a well recognisable but wide peaks appear in the narrow mesopore region, peculiarly overlapping with the distribution of the RGO. The pore size distribution revealed by the nitrogen is not influenced by the added GO (Fig. 5(d)).

It is not straightforward to compare adsorption results of various references is the field, as the laboratories apply different sol-gel conditions. Nevertheless, we made an attempt and selected the GO/resorcinol ratio as the only parameter for comparison and the apparent surface area as a typical characteristic, as practically it is the only phenomenon reported in all the papers. We limit this comparison to the $\mathrm{RF}$ rich composite, i.e. to $\mathrm{GO} /$ resorcinol mass ratio $<0.5$. Our observations, i.e., that the $\mathrm{GO}$ content does not really have a significant effect on the micropore texture probed by nitrogen adsorption agrees relatively well with the reference data in the limited GO content range (Fig. 8). The BET surface areas vary in the $600-800 \mathrm{~m}^{2} / \mathrm{g}$ range.

Figs. 9 and 10 show the SEM and TEM images of the samples. The characteristic spherical beads already seen in the polymer gels can be clearly distinguished in the

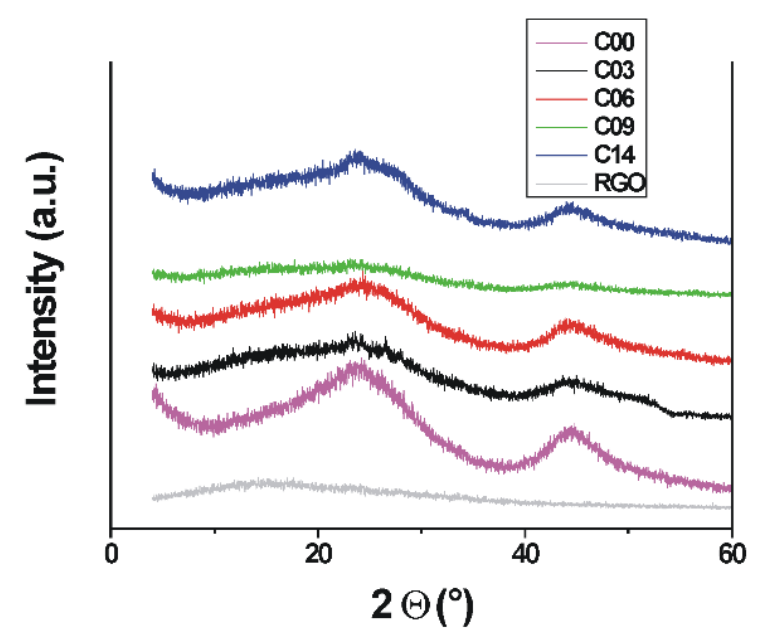

Fig. 7 Powder X-ray diffractograms of selected carbon aerogel samples and $\mathrm{GO}$ reduced at $800^{\circ} \mathrm{C}$

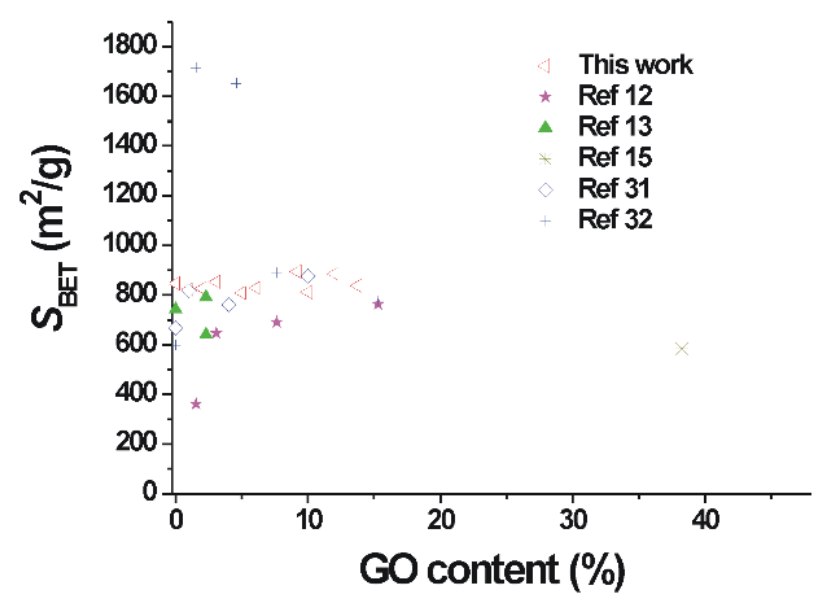

Fig. 8 Comparison of the apparent surface area of GO doped aerogels $[12,13,15,31,32]$.

electron microscopic images of the carbons. It is easy to recognize the veil-like feature of the reduced GO, i.e., in spite of the complex thermal decomposition and redox processes taking place during the pyrolysis the RGO sheets essentially keep their integrity. Holes yielded in the reduced graphene veil are clearly recognizable also in Figs. 9(c) and 9(f). As seen in the polymers, the beads grow within the space created among them only scarcely populating even the edges of the RGO itself [15]. The RGO veils are wrinkled and consist of several layers, typically 5-8 (Fig. 10(b)). In agreement with the X-ray diffractograms (Fig. 7) the high resolution TEM image confirms that the carbon samples are amorphous (Fig. 10(c)).

The improvement of the electrical conductivity was tested by a lab-made instrument (Fig. 11(a)). About $\sim 0.05 \mathrm{~g}$ of the samples was compressed in a polytetrafluoroethylene (PTFE) tube (internal cross section area 


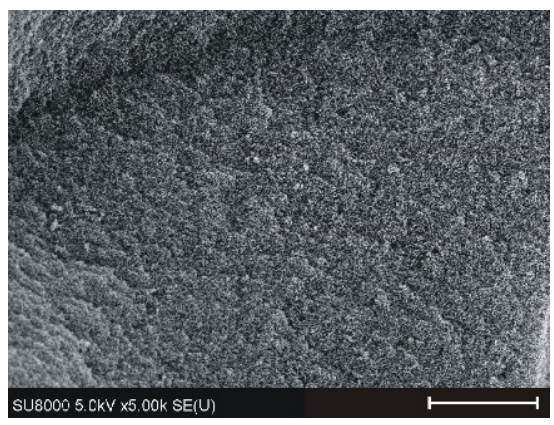

(a)

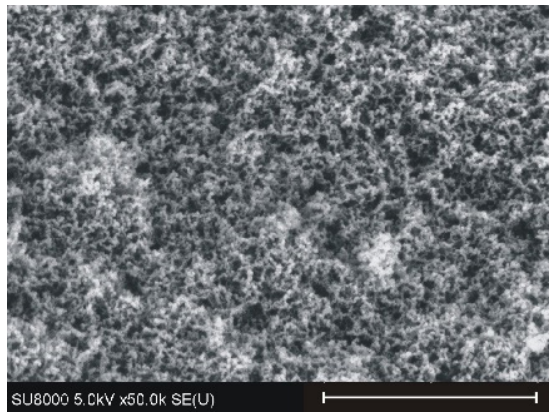

(d)

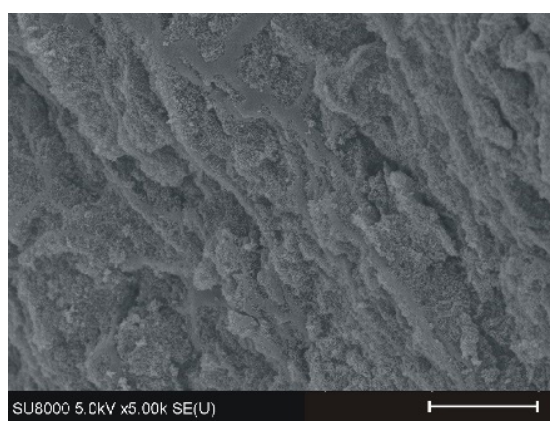

(b)

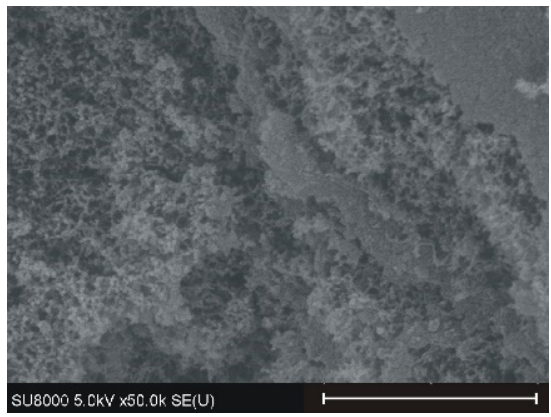

(e)

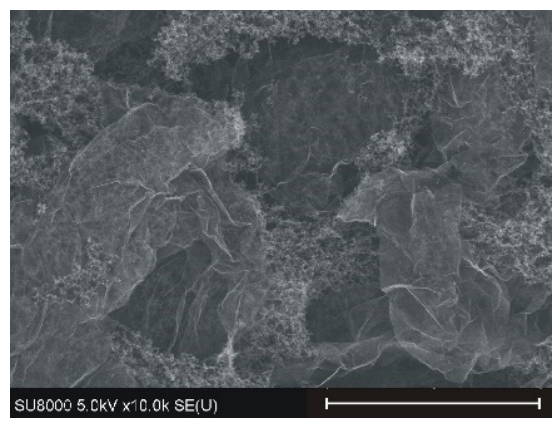

(c)

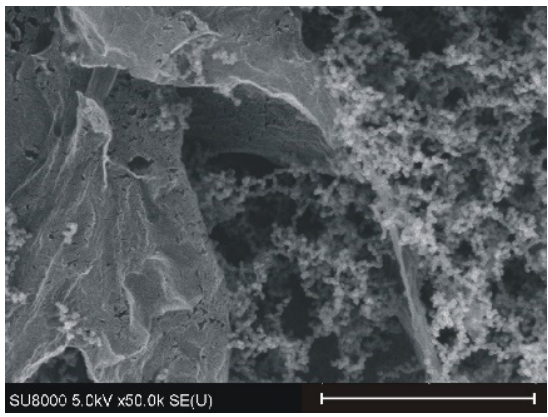

(f)

Fig. 9 SEM images of the $\mathrm{C} 00(\mathrm{a}, \mathrm{d})$, the $\mathrm{C} 05(\mathrm{~b}, \mathrm{e})$ and the $\mathrm{C} 14(\mathrm{c}, \mathrm{f})$ samples. Scale bars are $5 \mu \mathrm{m}$ and $1 \mu \mathrm{m}$ for the upper and lower row, respectively.

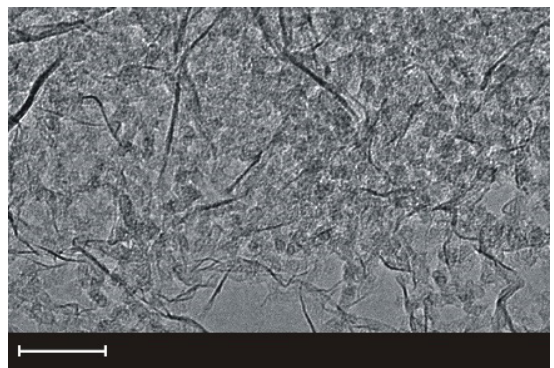

(a)

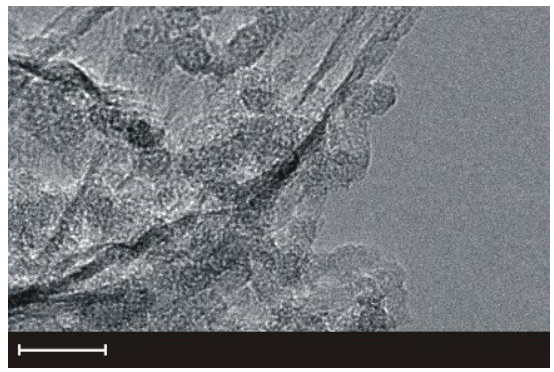

(b)

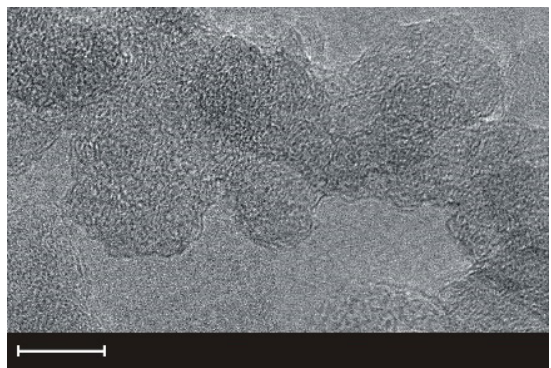

(c)

Fig. 10 The reduced graphene layers are wrinkled (a), several layer thick (b) and the beads are amorphous (c). The scale bars are $50 \mathrm{~nm}, 20 \mathrm{~nm}$ and $10 \mathrm{~nm}$, respectively.

$1 \mathrm{~cm}^{2}$ ) with a pressure of 0.5-5 $\mathrm{MPa}$. The results shown in Fig. 10 demonstrate that the GO-free carbon aerogel is conductive, but its conductivity is poor.

Incorporation of GO improves the electric conductivity as it was also reported by Ling et al. [31]. However, they found that the improvement was not linear in the 1-10\% GO content range. Our results show that in the GO concentration range studied the enhancement is linearly proportional to the GO content and by $10 \%$ GO content the conductivity of the GO-free sample doubles.

\section{Conclusions}

The textural properties of GO doped polymer and their carbonized derivatives were compared. The added GO has no significant influence on the textural properties either in polymer or carbon forms. The non-systematic effect of GO in the polymerisation - gelation step requires further investigation. Nevertheless, added GO improves the mechanical properties of the polymer aerogel and limits the shrinkage in the supercritical drying and the carbonization process. The GO is well distributed and practically retains its integrity with minor damages during the heat treatment. It does not seem to be integrated into the RF aerogel matrix. The samples contain pores of a wide size range, but the carbonization obviously enhances the microporosity. The apparent surface area increases by ca $25 \%$ due to the carbonization, but it is not influenced by the amount of the added 2D carbon nanoparticles. The effect on the electric properties is significant: in the concentration range studied $(0-14 \mathrm{~m} / \mathrm{m} \%$ GO related to the 

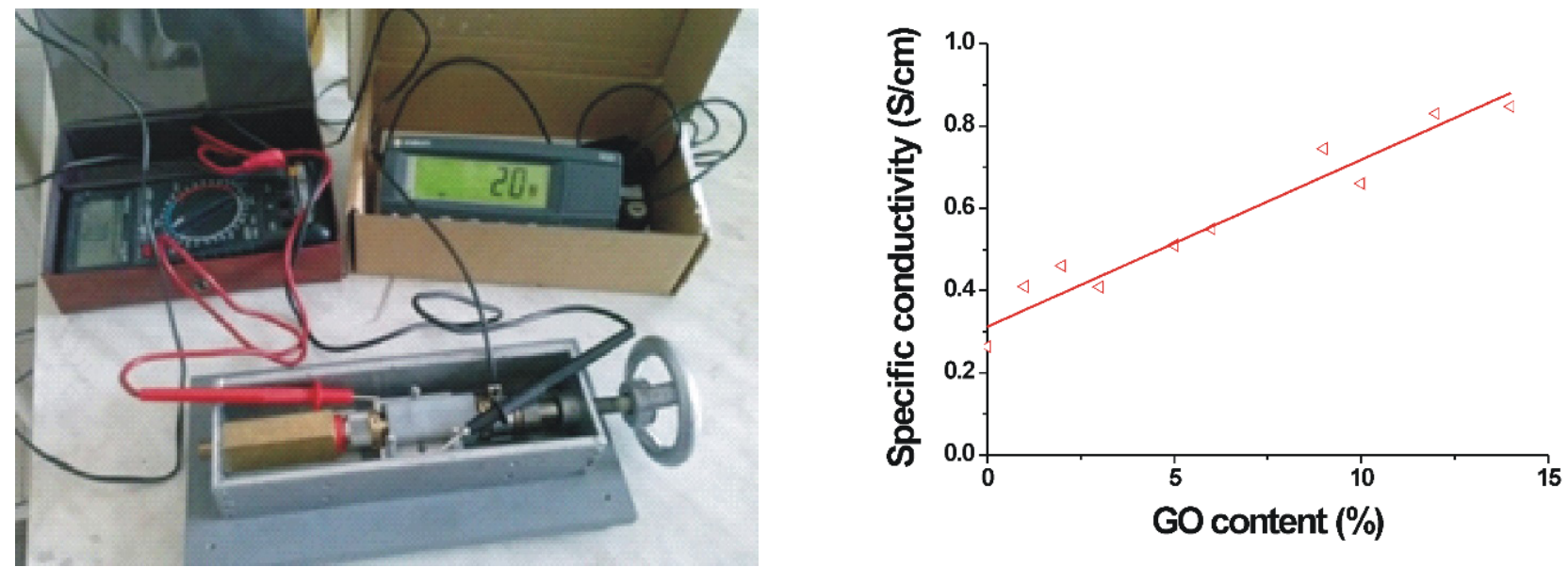

Fig. 11 The lab-made instrument for testing the electric conductivity in direct current (DC) (a) and the effect of the added GO on the conductivity (b). The symbols are experimental values, the red is guide for the eye.

resorcinol in the precursor solution) the electric conductivity increases linearly and is already doubled in the carbon obtained from the polymer with $10 \% \mathrm{GO}$.

\section{Acknowledgement}

The authors are grateful to J. Madarász for the XRD measurements, to E. Székely for her valuable contribution to supercritical drying, to K. Szarvas and G. da Silveira Gomes for their experimental work and to Gy. Bosznai for his technical assistance. We thank A. Szilágyi for his help in the stress-strain measurements. The images were

\section{References}

[1] Pekala, R. W. "Organic aerogels from the polycondensation of resorcinol with formaldehyde", Journal of Materials Science, 24(9), pp. 3221-3227, 1989.

https://doi.org/10.1007/BF01139044

[2] Shen, J., Dayong, Y. G. "Preparation and Application of Carbon Aerogels", In: Aegerter, A. M., Leventis, N., Koebel, M. M. (eds.) Aerogels Handbook, Springer, New York, NY, 2011, pp. 813-831. https://doi.org/10.1007/978-1-4419-7589-8_36

[3] Moreno-Castilla, C., Maldonado-Hódar, F. J. "Carbon aerogels for catalysis applications: An overview", Carbon, 43, pp. 455-465, 2005.

https://doi.org/10.1016/j.carbon.2004.10.022

[4] Nagy, B., Ábrahám, D., Dobos, G., Madarász, J., Onyestyák, G., Sáfrán, G., Geissler, E., László, K. "Molybdenum doped carbon aerogels with catalytic potential", Carbon, 66, pp. 210-218, 2014. https://doi.org/10.1016/j.carbon.2013.08.060

[5] Ábrahám, D., Nagy, B., Dobos, G., Madarász, J., Onyestyák, G., Trenikhin, M. V., László, K. "Hydroconversion of acetic acid over carbon aerogel supported molybdenum catalyst", Microporous and Mesoporous Materials, 190, pp. 46-53, 2014. https://doi.org/10.1016/j.micromeso.2014.01.021 taken in the Department of Biomedical Engineering BioNano Electronics Research Centre (Toyo University) lead by Prof. T. Maekawa within an EU project FP7-PEOPLE2010-IRSES-269267. Financial support from VEKOP2.3.2-16-2017-00013 is acknowledged. The VEKOP project is supported by the EU and by Hungary, co-financed by the European Regional Development Fund. The work is also part of the EU project NANOMED (H2020-MSCARISE-2016, \#734641). The research reported in this paper was supported by the BME-Nanonotechnology FIKP grant of EMMI (BME FIKP-NAT).

[6] Zhu, C., Liu, T., Qian, F., Han, T. Y.-J., Duoss, E. B., Kuntz, J. D., Spadaccini, C. M., Worsley, M. A., Li, Y. "Supercapacitors Based on Three-Dimensional Hierarchical Graphene Aerogels with Periodic Macropores", Nano Letters, 16(6), pp. 3448-3456, 2016.

https://doi.org/10.1021/acs.nanolett.5b04965

[7] Lin, Y., Liu, F., Casano, G., Bhavsar, R., Kinloch, I. A., Derby, B. "Pristine Graphene Aerogels by Room-Temperature Freeze Gelation", Advanced Materials, 28(36), pp. 7993-8000, 2016. http://doi.org/10.1002/adma.201602393

[8] Maillard, F., Simonov, P. A., Savinova, E. R. "Carbon materials as supports for fuel cells electrocatalysts", In: Serp, P., Figueiredo, J. L. (eds.) Carbon Materials for Catalysis, John Wiley \& Sons, Inc., Hoboken, N.J., USA, 2009, pp. 429-481. https://doi.org/10.1002/9780470403709.ch12

[9] Markoulidis, F., Lei, C., Lekakou, C., Duff, D., Khalil, S., Martorana, B., Cannavaro, I. "A method to increase the energy density of supercapacitor cells by the addition of multiwall carbon nanotubes into activated carbon electrodes", Carbon, 68, pp. 58-66, 2014. https://doi.org/10.1016/j.carbon.2013.08.040 
[10] Qian, H., Kucernak, A. R., Greenhalgh, E. S., Bismarck, A., Shaffer, M. S. P. "Multifunctional Structural Supercapacitor Composites Based on Carbon Aerogel Modified High Performance Carbon Fiber Fabric", ACS Applied Materials \& Interfaces, 5(13), pp. 6113-6122, 2013.

https://doi.org/10.1021/am400947j

[11] Wang, W., Xu, H., Chen, J., Shen, Y., Bertóti, I., Guo, X., Shi, X., Elsiddig, Z. " Structure, Mechanical and Electrochemical Properties of Thermally Reduced Graphene Oxide-poly (Vinyl Alcohol) Foams", Periodica Polytechnica Chemical Engineering, 62(1), pp. 8-20, 2018.

https://doi.org/10.3311/PPch.11148

[12] Meng, F., Zhang, X., Xu, B., Yue, S., Guo, H., Luo, Y. "Alkalitreated graphene oxide as a solid base catalyst: Synthesis and electrochemical capacitance of graphene/carbon composite aerogels", Journal of Materials Chemistry, 21(46), pp. 18537-18539, 2011. https://doi.org/10.1039/c1jm13960f

[13] Lee, Y. J., Park, H. W., Kim, G.-P., Yi, J., Song, I. K. "Supercapacitive electrochemical performance of graphene-containing carbon aerogel prepared using polyethyleneimine-modified graphene oxide", Current Applied Physics, 13(5), pp. 945-949, 2013. https://doi.org/10.1016/j.cap.2013.02.005

[14] Worsley, M. A., Pauzauskie, P. J., Olson, T. Y., Biener, J., Satcher, J. H., Jr., Baumann T. F. "Synthesis of Graphene Aerogel with High Electrical Conductivity", Journal of the American Chemical Society, 132(40), pp. 14067-14069, 2010. https://doi.org/10.1021/ja1072299

[15] Worsley, M. A., Olson, T. Y., Lee, J. R. I., Willey, T. M., Nielsen, M. H., Roberts, S. K., Pauzauskie, P. J., Biener, J., Satcher, J. H., Jr., Baumann, T. F. "High Surface Area, sp²-Cross-Linked Three-Dimensional Graphene Monoliths", The Journal of Physical Chemistry Letters, 2(8), pp. 921-925, 2011. https://doi.org/10.1021/jz200223x

[16] Marcano, D. C., Kosynkin, D. V., Berlin, J. M., Sinitskii, A., Sun, Z., Slesarev, A., Alemany, L. B., Lu, W., Tour, J. M. "Improved Synthesis of Graphene Oxide", ACS Nano, 4(8), pp. 4806-4814, 2010. https://doi.org/10.1021/nn1006368

[17] Lin, C., Ritter, J. A. "Effect of synthesis $\mathrm{pH}$ on the structure of carbon xerogels", Carbon, 35(9), pp. 1271-1278, 1997. https://doi.org/10.1016/S0008-6223(97)00069-9

[18] Czakkel, O., Marthi, K., Geissler, E., László, K. "Influence of drying on the morphology of resorcinol-formaldehyde-based carbon gels", Microporous and Mesoporous Materials, 86(1-3), pp. 124-133, 2005.

https://doi.org/10.1016/j.micromeso.2005.07.021

[19] Horkay, F., Zrínyi, M. "Studies on the mechanical and swelling behavior of polymer networks based on the scaling concept. 4 . Extension of the scaling approach to gels swollen to equilibrium in a diluent of arbitrary activity", Macromolecules, 15(5), pp. 1306-1310, 1982. https://doi.org/10.1021/ma00233a018

[20] Brunauer, S., Emmett, P. H., Teller, E. "Adsorption of Gases in Multimolecular Layers", Journal of the American Chemical Society, 60(2), pp. 309-319, 1938. https://doi.org/10.1021/ja01269a023
[21] Dubinin, M. M., Radushkevich, L. V. "The equation of the characteristic curve of the activated charcoal", Proceedings of the Academy of Sciences of the USSR. Chemistry Section, 55, pp. 331-337, 1947.

[22] Barret, E. P., Joyner, L. G., Halenda, P. H. "The Determination of Pore Volume and Area Distributions in Porous Substances. I. Computations from Nitrogen Isotherms", Journal of the American Chemical Society, 73(1), pp. 373-380, 1951. https://doi.org/10.1021/ja01145a126

[23] Berke, B., Sós, L., Bérczes, V., Domján, A., Porcar, L., Czakkel, O., László, K. "Graphene derivatives in responsive hydrogels: Effect of concentration and surface chemistry", European Polymer Journal, 93, pp. 717-725, 2017. https://doi.org/10.1016/j.eurpolymj.2017.02.046

[24] Manek, E., Berke, B., Miklósi, N., Sajbán, M., Domán, A., Fukuda, T., Czakkel, O., László, K. "Thermal sensitivity of carbon nanotube and graphene oxide containing responsive hydrogels", Express Polymer Letters, 10(8), pp. 710-720, 2016. http://doi.org/10.3144/expresspolymlett.2016.64

[25] Guo, K., Song, H., Chen, X., Du, X., Zhong, L. "Graphene oxide as an anti-shrinkage additive for resorcinol-formaldehyde composite aerogels", Physical Chemistry Chemical Physics, 16(23), pp. 11603-11608, 2014.

https://doi.org/10.1039/c4cp00592a

[26] Liu, L., Yang, J., Meng, Q. "Graphene cross-linked phenol-formaldehyde hybrid organic and carbon xerogel during ambient pressure drying", Journal of Sol-Gel Science and Technology, 66(1), pp. 1-5, 2013. https://doi.org/10.1007/s10971-012-2958-5

[27] Liu, L., Yang, J., Meng, Q. "The preparation and characterization graphene-cross-linked phenol-formaldehyde hybrid carbon xerogels", Journal of Sol-Gel Science and Technology, 67(2), pp. 304-311, 2013. https://doi.org/10.1007/s10971-013-3080-z

[28] Thommes, M., Kaneko, K., Neimark, A. V., Olivier, J. P., RodriguezReinoso, F., Rouquerol, J., Sing, K. S. W. "Physisorption of gases, with special reference to the evaluation of surface area and pore size distribution (IUPAC Technical Report)", Pure and Applied Chemistry, 87(9-10), pp. 1051-1069, 2015. https://doi.org/10.1515/pac-2014-1117

[29] Justh, N., Berke, B., László, L., Szilágyi, I. M. "Thermal analysis of the improved Hummers' synthesis of graphene oxide", Journal of Thermal Analysis and Calorimetry, 131(3), pp. 2267-2272, 2018. https://doi.org/10.1007/s10973-017-6697-2

[30] Wang, S., Ábrahám, D., Vallejos-Burgos, F., Geissler, E., László, K., Takeuchi, K., Endo, M., Kaneko, K. "Distorted Graphene Sheet Structure-Derived Latent Nanoporosity", Langmuir, 32(22), pp. 5617-5622, 2016. https://doi.org/10.1021/acs.langmuir.6b00483

[31] Ling, Z., Wang, G., Dong, Q., Qian, B., Zhang, M., Lia, C., Qiu, J. "An ionic liquid template approach to graphene-carbon xerogel composites for supercapacitors with enhanced performance", Journal of Materials Chemistry A, 2(35), pp. 14329-14333, 2014. https://oi.org/10.1039/c4ta02223h

[32] Zhang, K., Ang, B. T., Zhang, L. L., Zhao, X. S., Wu, J. "Pyrolyzed graphene oxide/resorcinol-formaldehyde resin composites as high-performance supercapacitor electrodes", Journal of Materials Chemistry, 21(8), pp. 2663-2670, 2011.

https://oi.org/10.1039/c0jm02850a 